\title{
The Learning-Related Activity That Develops in the Pontine Nuclei During Classical Eye- Blink Conditioning Is Dependent on the Interpositus Nucleus
}

\author{
Robert E. Clark, ${ }^{1}$ Elizabeth B. Gohl, and David G. Lavond \\ Departments of Psychology and Biological Sciences \\ University of Southern California \\ Los Angeles, California 90089-2520
}

\begin{abstract}
A growing body of research now implicates the cerebellum in the formation and storage of the critical neural plasticity that subserves the classically conditioned eye-blink response. Previous anatomical, physiological, and behavioral research suggests that auditory-conditioned stimulus information is routed to the cerebellum by the pontine nuclei. However, it has also been observed from multiple unit recordings that some populations of pontine cells, in addition to showing auditory-evoked responses, also show changes in activity that is learning-related. It is unknown whether this learning-related activity is generated by the pontine cells or whether it is generated by some other structure and projected to the pontine nuclei. Because the cerebellum has been implicated in the formation of the essential plasticity that subserves this learned behavior, we examined how multiple unit recordings of learning-related activity within the pontine nuclei are affected by reversible inactivation of the interpositus nucleus of the cerebellum. The results indicated clearly that when the interpositus nucleus was inactivated, the learning-related activity in the pontine nuclei was abolished completely and the auditory stimulus-evoked activity was unaffected. In contract, when the facial nucleus was inactivated, both the auditory stimulus and the learning-related activity
\end{abstract}

${ }^{1}$ Corresponding author. were still present. These results indicate that the learning-related activity exhibited by some populations of pontine nuclei cells is dependent on the interpositus nucleus and may represent feedback from the cerebellum.

\section{Introduction}

Classical conditioning of the rabbit eye-blink or nictitating membrane (NM) response has been used extensively to study the neurobiology of simple associative memory in mammals. Compelling evidence now exists that implicates the cerebellum as essential for the formation and storage of this eye-blink engram. This research deals primarily with simple delay conditioning. For more complex conditioning tasks, like trace conditioning, the hippocampus is also critical (Kim et al. 1995). For simple delay conditioning, converging evidence from permanent lesion, stimulation, and recording studies have made possible the construction of a relatively complete theoretical circuit that includes neural pathways for the conditioned stimulus (CS), the unconditioned stimulus (US), the conditioned response (CR), and the unconditioned response (UR). Auditory CS information is relayed from the pontine nuclei, through mossy fibers, to the cerebellar cortex and interpositus nucleus, whereas somatosensory US information (typically an air puff) is relayed from the trigeminal complex to the inferior olive and then, by climbing fibers, to the cerebellar cortex and interpositus. The convergence of CS and US information in the cerebellum makes possible the neural plasticity that underlies the CR, which is then routed out of the cerebellum through the red nucleus to motor nuclei responsible for driving the NM response (for

LEARNING \& MEMORY 3:532-544 (C) 1997 by Cold Spring Harbor Laboratory Press ISSN1072-0502/97 \$5.00

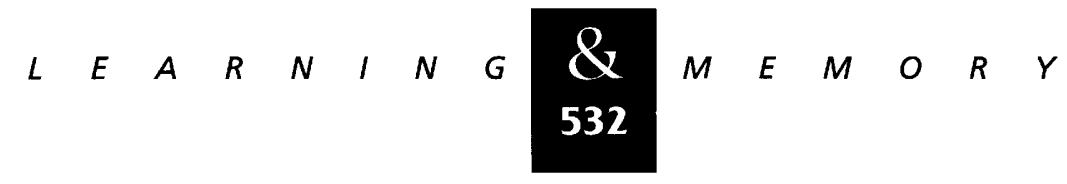


an extensive review of this circuit, see Lavond et al. 1993).

The pontine nuclei are of interest because they have been implicated in participating in the CS pathway for the conditioned eye-blink response. Anatomical and electrophysiological studies have indicated that the pontine nuclei send mossy fibers through the middle cerebellar peduncle to the cerebellar cortex (Brodal and Jansen 1946) and to the interpositus nucleus (Steinmetz and Sengelaub 1992; Mihailoff 1993; J. Tracy, D.J. Krupa, N.L. Bernasconi, J.S. Grethe, and R.F. Thompson, unpubl.).

Stimulation of the pontine nuclei or of the middle cerebellar peduncie can be used as an effective conditioning stimulus (Steinmetz et al. 1985, 1989). In fact, pontine stimulation as a CS yields more rapid acquisition than exteroceptive CSs. As with exteroceptive CSs, when CS stimulation alone trials are presented, the learned behavior extinguishes (Steinmetz et al. 1986). Furthermore, animals trained with pontine stimulation as the CS develop a neural model in the interpositus nucleus that is indistinguishable from the model that develops with a tone CS (i.e., activity that is associated with and predictive of the learned behavioral response). When these animals are switched to a tone CS, considerable transfer is evident-perfect in some cases (Steinmetz 1990). This argues that pontine stimulation activates a significant portion of the neural elements normally activated with a tone $\mathrm{CS}$. There is no transfer when a light CS is substituted. Lesion of the interpositus also abolish the CRs established with pontine CS stimulation (Steinmetz et al. 1986).

Middle cerebellar peduncular lesions abolish CRs to auditory, visual, and tactile CSs (Solomon et al. 1986), whereas discrete lesions of the lateral pontine nuclei abolish CRs to a tone, but not to a light CS (Steinmetz et al. 1987). Recording studies have indicated that short latency auditory-evoked responses are present in the lateral pontine nuclei (Steinmetz et al. 1986) and this region receives primary auditory projections (Aitkin and Boyd 1978). These studies indicate that all CS modalities tested are relayed to the cerebellum by the middle cerebellar peduncle, whereas the lateral pontine nuclei seem to be specifically involved in the routing of auditory CS information to the cerebellum through the middle cerebellar peduncle.

Although the data presented above provide strong support for the pontine nuclei participating in the CS pathway, other factors need to be con- sidered. For example, although the auditoryevoked response in the pontine nuclei is wellknown, there is evidence suggesting that this region may also receive somatosensory information from the air puff (Lavond et al. 1981). This means that the pontine nuclei could receive convergent CS and US information and could be the essential site of plasticity. Couple this with the observation that this region also shows learning-related neural unit activity in well-trained animals (McCormick et al. 1983), a case can be made for this region being the possible site of essential plasticity that then projects the model to the cerebellum. However, an alternative interpretation is that this unit model could be formed in the cerebellum and projected to the pontine nuclei as feedback.

The strategy we adopted here to examine this possibility has been used successfully previously to study the relationship of the trigeminal and interpositus nuclei (Clark and Lavond 1996) and the interpositus and bilateral regions of the cerebellar cortex (Clark et al. 1997). Briefly, animals were well-trained for the classically conditioned eye blink response and then multiple unit activity was sampled from the pontine nuclei. The interpositus nucleus was then temporarily inactivated by cooling while the multiple unit activity was monitored continually for changes. As a control, we also cooled the facial nucleus during recording from the pontine nuclei. The facial nucleus is critically involved in the expression of both the eye-blink CR and UR (Cegavske et al. 1976), although it is not critical for the formation of the conditioned response (Krupa et al. 1996; Clark et al. 1997; A.A. Zhang and D.G. Lavond, unpubl.).

We chose to use a cooling probe, which reversibly inactivates cell bodies without affecting fibers (Brooks 1983), because this study required greater control for numerous inactivations and reversal of inactivations during a single training session. The cooling probe possesses the ideal characteristics for this particular type of study because of its ability to produce a rapidly induced ( $<30 \mathrm{sec})$ lesion and a rapidly reversed (<30 sec) lesion (Clark et al. 1992; Clark and Lavond 1993). Previously, we have demonstrated that the interpositus can be reversibly lesioned repeatedly without destroying the conditioned memory trace (Clark et al. 1992; Clark and Lavond 1996). In conjunction with multiple cooling periods, we used a movable recording microelectrode that enabled us to collect a significant amount of data from each subject during a single training session.

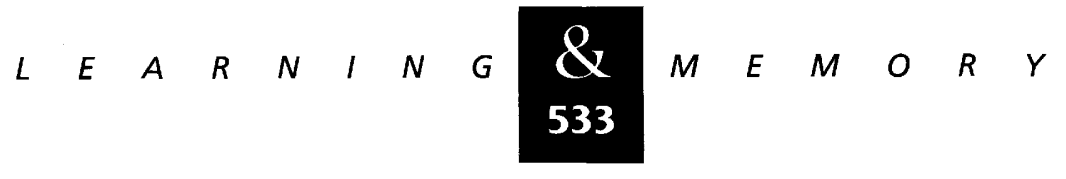


Clark et al.

\section{Materials and Methods}

SUBJECTS

The subjects for this experiment $(N=22)$ were adult male New Zealand white rabbits (Oryctolagus cuniculus) weighing $2.0 \pm 0.2 \mathrm{~kg}$ at the start of the experiment. All rabbits were housed individually and maintained on a 12-hr light/12-hr dark cycle and given unlimited access to water and food. The rabbits were cared for by the experimenters and by the staff and veterinarians of the University of Southern California. Care and treatment conformed to guidelines of the American Association for the Accreditation of Laboratory Animal Care (AAALAC), American Psycholgical Association (APA), and the National Institutes of Health (NIH).

\section{SURGERY}

All rabbits were operated on with aseptic techniques before any training. Anesthesia was induced with $5 \mathrm{mg} / \mathrm{kg}$ of xylazine and $60 \mathrm{mg} / \mathrm{kg}$ of ketamine and maintained with $1 \%-3 \%$ halothane. Cooling probes based on the design of Zhang et al. (1986) were implanted into one of two brain regions. Fifteen rabbits had cooling probes placed near the interpositus nucleus (AP +0.5, ML +6.5, DV -14.0, from lambda), and seven rabbits had cooling probes placed near the facial motor nucleus (AP -14.0, ML +2.5, DV -21.0, from bregma) with bregma $1.5 \mathrm{~mm}$ higher than lambda. Rabbits were fitted with an electrode base over a hole drilled in the cranium and centered in an AP and ML plane over the right pontine nuclei. Later, during testing in well-trained animals, a recording electrode was lowered with a Narishige micromanipulator (MO-99), which was attached to the implanted base. The manipulator allows for multiple targets to be monitored in the same subject. The cooling probe, electrode base, and socket for holding a minitorque potentiometer and air puff hose were fixed with stainless steel skull screws and dental acrylic. Prophylactics and analgesics were given as needed. Seven days were allowed for recovery from surgery.

\section{TRAINING}

All rabbits were habituated to the training apparatus for $1 \mathrm{hr}$ on the day before training. Each rabbit was held in a standard Plexiglas rabbit restrainer. An airhose for delivering the air puff and a minitorque potentiometer for measuring the nictitating membrane response were attached to a socket cemented to the rabbit's cranium.

Training for classical conditioning began the next day. The CS was a 352-msec, $1-\mathrm{kHz}, 85-\mathrm{dB}$ SPL, free-field tone. The US was a 100-msec, 2.1$\mathrm{N} / \mathrm{cm}_{2}$ (source pressure) air puff delivered to the cornea. On paired trials the CS and US coterminate, creating a 252-msec interstimulus interval. Each daily training session consisted of 108 total trials composed of 12 blocks of nine trials per block. In each block the first trial was a tone alone test trial and the fifth trial was an air puff alone test trial, with the remaining trials being paired tone and air puff. Animals were trained until they responded at $>70 \%$ CRs on 2 consecutive days. A CR is defined as any movement of the nictitating membrane $\geqslant 0.5 \mathrm{~mm}$ during the $252-\mathrm{msec}$ CS period. In animals that had cooling probes placed near the facial nucleus, eyelid electromyographic (EMG) was analyzed in addition to the NM. This was done because the facial nucleus controls the muscles involved in generating the eye blink (orbicularis oculi muscles), whereas the accessory abducens controls the NM response (retractor bulbus muscle).

When an animal was well-trained the mapping procedure began. Animals were placed in the restrainer and equipment was attached as above. In addition, the protective base cover was removed and an electrode micromanipulator attached in its place. A coolant (we have used Freon-12, Freon-22, and HFC134a as the coolant) delivery tube and an exhaust tube were attached to the cooling probe. The electrode (made of 00 stainless steel insect pins and insulated with a minimum of six baked coats of Epoxylite, with 20-60 mm of exposed tips by scraping) was lowered until neural recording could be identified on a Hitachi digital storage oscilloscope (model VC-6025). One block of normal training was given after which the presence or absence of conditioning-related unit activity could be accessed. If the unit activity appeared to be related to the eye-blink behavior then the cooling probe was activated and the animal tested for one block. We used a minimum criterion of 2:1 signal-to-noise ratio for our analyzed recordings, although most were $3: 1$ or greater. We estimated that the number of units we typically discriminated during recording (based on height) to be three to five neurons. The cooling probe was then turned off and the electrode lowered further. This procedure was re-

$$
\text { n...... }
$$


peated until the session ended or the electrode reached the ventral dura matter, which could be distinguished easily by the oscilloscope display. At this point marking lesions were made along the length of the electrode path where relevant unit activity was encountered by passing $100 \mathrm{~mA}$ of current through the tip for $10 \mathrm{sec}$.

\section{APPARATUS}

All testing took place inside Industrial Acoustics individual sound attenuating chambers. The stimulus delivery and timing were controlled by IBM-PC/XT clones with programs written in 8088 machine language and Forth using an in-house designed XT card interface (Lavond and Steinmetz 1989). The computers also collected the behavioral and electrophysiological data in 4-msec time bins and analyzed the data on line. The nictitating membrane data were collected through an 8-bit A/D converter. The neural unit data were collected with an extracellular multiple unit stainless steel electrode with activity amplified by A-M Systems model 1700 4-channel amplifier (10K gain, 300- to 5000-Hz bandpass filtering). Spike amplitude was passed to a level discriminator that digitized the activity, which was then collected by the computer for construction of peristimulus histograms. All data were stored on floppy disks for later retrieval.

The cooling probes consisted of a 30-gauge inner stainless steel tubing inside a 19-gauge stainless steel tube. The expansion of coolant from the 30- to 19-gauge tubing absorbs heat. The rate of coolant delivery determines cooling, which could be monitored with a constantan-stainless steel thermocouple. The delivery rate was calibrated to create a tip temperature of $0^{\circ} \mathrm{C}$, causing the target tissue to range in temperature from $8.5^{\circ}$ to $20^{\circ} \mathrm{C}$. This range is consistent with suppressing neuronal activity but having little effect on conduction of fibers of passage (Brooks 1983; Zhang et al. 1986).

\section{HISTOLOGY}

At the end of a particular mapping session, subjects were sacrificed with an overdose of sodium pentobarbital. They were then perfused intraaortically with physiological saline followed by $10 \%$ formalin, the brains were removed and placed in perfusate for several days. The brains were then blocked and embedded in an albumin-gelatin ma- trix, and frozen sectioned at $80 \mu \mathrm{m}$. Every other section was mounted onto chrome-alum-subbed slides, dried and stained with cresyl violet for cell bodies and Prussian Blue to localize the marking lesions. The sections were coverslipped and dried, then examined microscopically and recorded on brain section diagrams for placements of the cooling probe and recording electrodes.

\section{DATA ANALYSIS}

This study was only concerned with unit activity during periods of normal training and training while cooling. Unit activity was examined with peristimulus time histograms and subjected to statistical analysis with $\mathrm{z}$ scores to quantify the degree of activity associated with learning, which is our working definition of a unit "model," or the effect cooling had on stimulus evoked responses or baseline activity. This is similar to methods used in the past for analyzing unit data (Olds et al. 1972; Thompson 1976). Each trial has three 252-msec periods: the pre-CS (baseline), CS, and US periods. Each of these periods was further divided into three 84-msec epochs. During the training session, for each block of trials, a grand mean and standard error were calculated across all trials in a particular block using the 84-msec epoch immediately before the onset of the CS. This grand mean and standard error were used to calculate $\mathrm{z}$ scores for the three 84-msec CS epochs and the three 84-msec US epochs for each individual block. Any change in unit activity resulting in a $z$ score of +1.65 or greater (a one-tailed significance level of 0.05 ) during any of the 84-msec epochs was considered a significant change in activity. A grand mean was calculated for all of the 84-msec pre-CS epochs. $z$ Scores were then calculated for the pre-CS epochs of individual block of trials. By comparing the pre-CS z score for one block of trials with the following pre-CS period $\mathrm{z}$ score during cooling, we can determine whether cooling had any effect on baseline activity.

\section{Results}

\section{BEHAVIORAL RESULTS}

All animals, regardless of cooling probe placement, reached a level of performance of $80 \%$ CRs for at least two consecutive training sessions by day 5 of normal training. Cooling the interpositus

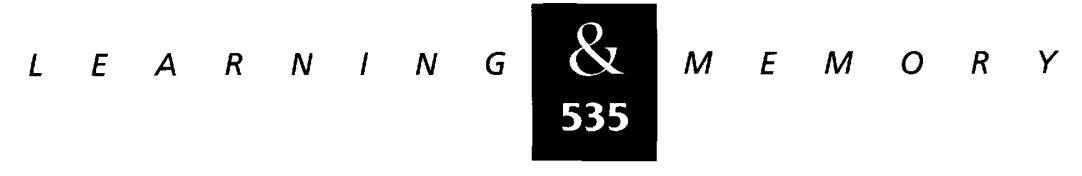


Clark et al.

abolished CRs completely for the duration of cooling in all animals except two. Histology revealed that the cooling probes for these animals were located in the lateral portion of the dentate nucleus and their data are not included in the analysis. For an analysis of the UR amplitude, the data were pooled for all animals with cooling probes placed near the interpositus regardless of recording locations. For each session where cooling was used, the UR amplitudes on air puff alone trials were separated into two conditions. The first condition was UR amplitudes on US alone trials during normal training. The second condition was UR amplitudes on US alone trials during interpositus cooling. This allows a maximum of six US alone trials during cooling and six US alone trials during normal training per session. Several animals received more than one session of cooling training. In these cases more trials could be included in the analysis. The two conditions of UR amplitudes on US alone trials were then averaged, therefore two values for UR amplitude were obtained for each animals-UR amplitude during interpositus cooling and UR amplitude during normal training. These values were then analyzed statistically. Results show that there was no statistical difference between the UR amplitudes during cooling and normal training (nor$\mathrm{mal}=6.97 \pm 3.52 \mathrm{~mm}$; cooling $5.70 \pm 2.43 \mathrm{~mm}$; $t_{32}=1.29, P=0.21$ not significant). Like interpositus cooling, facial nucleus cooling abolished all CRs completely [behavioral data from this group have also been reported elsewhere; Clark and Lavond 1996]. However, cooling the facial nucleus also abolished NM URs. The data for UR amplitude during normal training and cooling were analyzed in the same way as the URs for interpositus cooling (normal $=6.36 \pm 1.55 \mathrm{~mm} ;$ cooling $=0.18 \pm 0.13$ $\left.\mathrm{mm} ; t_{6}=10.50, P=0.0001\right)$. This finding was extended to eyelid EMG. The $\mathrm{z}$ scores were calculated for air puff alone trials during normal training and training during cooling. As above, $z$ scores for normal and cooling training were calculated for each animal and subjected to a statistical analysis that revealed a significant difference between cooling and normal training (normal $\mathrm{z}=4.73 \pm 1.43$; cooling $\mathrm{z}=0.503 \pm 0.302 ; t_{6}=7.60, P=0.0003$ ). This indicated that cooling the facial nucleus abolished both NM and EMG URs.

\section{RECORDINGS}

One hundred thirty-nine recordings were deemed acceptable for analysis (units free of arti- facts caused by the sinusoidal tone wave or a struggling animal and an acceptable signal to noise ratio). Of these recordings, 129 were obtained in animals with cooling probes located near the interpositus nucleus and 19 were obtained from animals with cooling probes located near the facial nucleus.

The patterns of these units could be divided into four basic groups. (1) Units that showed no appreciable response to the conditioning stimuli or the behavioral response. These units are classified as "no model" responses (N). (2) Units that showed an increase in activity that in peristimulus histograms showed a similar amplitude/time course to the learned behavioral response (i.e., a $\mathrm{z}$ score of $\geqslant 1.65$ occurring in the second and third epochs of the CS period and the first and sometimes second epochs of the US period). These units are classified as "model" responses (M). (3) Units that showed a large phasic response to the tone onset. In peristimulus histograms these units showed a phasic response to the tone onset, which occurred rapidly and then decayed back to baseline usually within $100 \mathrm{msec}$. These are classified as "tone response" units (T). (4) Units that showed a large phasic response to the tone onset, which decayed rapidly toward baseline before increasing in activity that in peristimulus histograms showed a similar amplitude/time course to the learned behavioral response. These units are classified as "tone plus model" responses (TM).

Figure 1 is a reconstruction of the spatial distribution of these recording sites. Regarding this distribution two caveats must be understood. First, there are many more recording sites showing responses that were, in one fashion or another, related to the conditioning stimuli or behavior than sites that showed no related activity. This should not be interpreted as an accurate ratio attributable to the methodologies used by this study. We were interested in conditioning related activity and this guided our choice of locations to mark and analyze during normal training and training while cooling. Often when the electrode was lowered and no related activity was discernible, the electrode was lowered to a new location. Therefore, most of our marking lesions were reserved for those locations that showed conditioning-related activity. Most of our negative recording sites were obtained from electrode paths that never showed discernible activity, in which cases these tracts were marked. Second, although we have numerous recordings from most regions of the pontine nuclei, we were

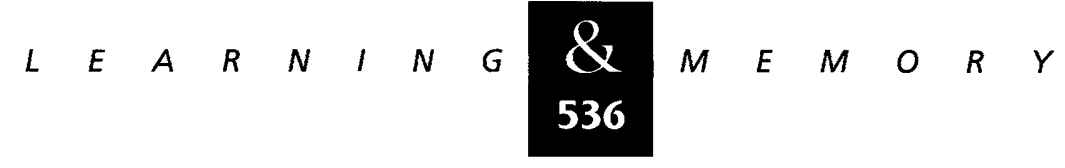



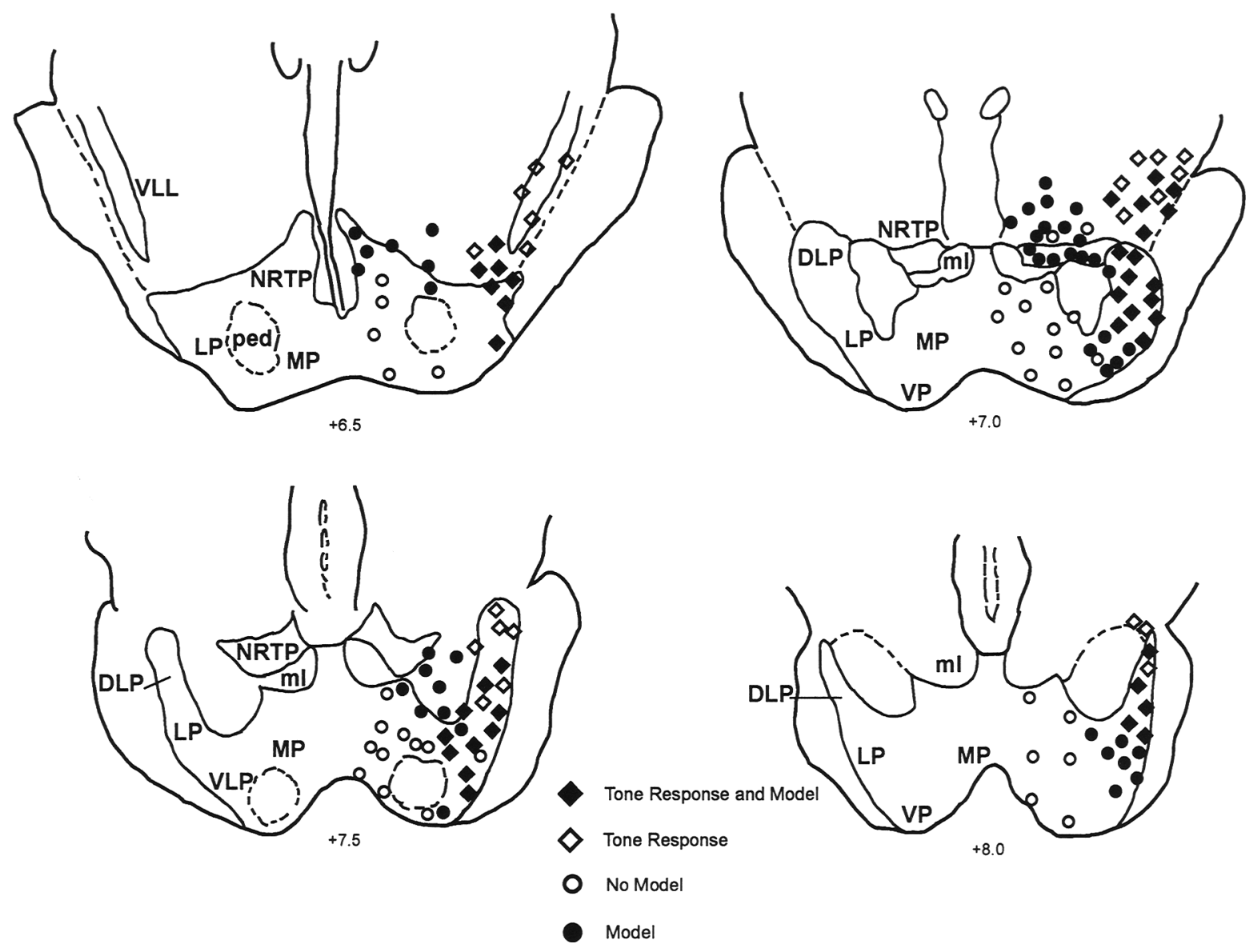

Figure 1: Sections through the pontine nuclei at 4 rostrocaudal levels showing the spatial distribution of multiple unit extracellular recordings obtained during normal training. (DPL) Dorsolateral pontine nucleus; (LP) lateral pontine nucleus; $(\mathrm{VL})$ ventrolateral nucleus; (MP) medial pontine nucleus; (NRTP) nucleus reticularis tegmenti pontis; (VLL) ventral nucleus of the lateral lemniscus; (ped) pyramidal tract; $(\mathrm{ml})$ medial lemniscus.

unable to cover the entire area completely. Therefore, regions that did not show conditioning-related activity are in no way definitive evidence that such an area is not involved in the performance or learning of the conditioned response. However, our recording sites were of sufficient number and diversity of location to allow us to make a reasonable approximation of the distribution of the different types of responses.

The basic distribution of response patterns can be summarized as follows: Most of the T responses were encountered in the very dorsolateral regions of the pontine gray. They tended to cluster near the dorsal edge of the dorsolateral pontine nucleus and the nucleus of the lateral lemniscus. TM responses were most frequently observed in regions lateral to the pyramidal tract and on the same dorsal/ventral plane as the pyramidal tract. The $\mathrm{M}$ re- sponses were distributed in most of the region dorsal to the pyramidal tract and sometimes ventrolateral to the tract. A large portion of these $M$ responses were clustered in and around the nucleus reticularis tegmenti pontis (NRTP). Finally, most the $\mathrm{N}$ responses were confined to regions medial and ventromedial to the pyramidal tract. Table 1 lists all of the units that were analyzed by response type, ratio of response type to other responding units, and the number of response type units encountered in various nuclei of the pontine region.

\section{RECORDINGS DURING COOLING INTERPOSITUS}

Simply stated, cooling the interpositus had no effect on baseline activity or on the phasic tone

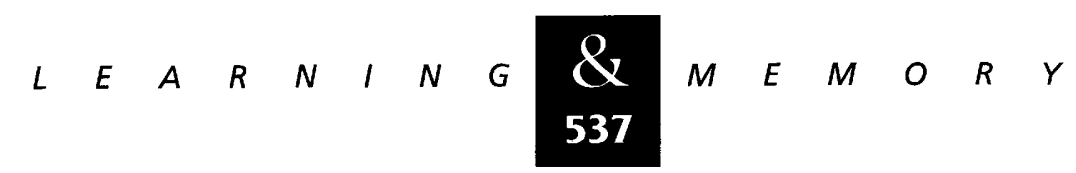


Clark et al.

Table 1: Response type frequency distribution

\begin{tabular}{|c|c|c|c|c|}
\hline \multicolumn{5}{|c|}{ A. Recorded unit totals } \\
\hline $\begin{array}{l}\text { Total } \\
\text { recorded } \\
\text { units }\end{array}$ & $\begin{array}{l}\text { Total } \\
\text { responding } \\
\text { units }\end{array}$ & & $\begin{array}{l}\text { Auditory } \\
\text { response } \\
\text { units }\end{array}$ & $\begin{array}{l}\text { Model } \\
\text { response } \\
\text { units }\end{array}$ \\
\hline 139 & 104 & & 60 & 82 \\
\hline \multicolumn{5}{|c|}{ B. Auditory and model response type (\%) } \\
\hline $\begin{array}{l}\text { Response } \\
\text { type }\end{array}$ & $\begin{array}{l}\text { Total no. } \\
\text { of units }\end{array}$ & $\begin{array}{c}\text { Responding } \\
\text { units } \\
(\%)\end{array}$ & $\begin{array}{c}\text { Auditory } \\
\text { units } \\
(\%)\end{array}$ & $\begin{array}{c}\text { Model } \\
\text { units } \\
(\%)\end{array}$ \\
\hline $\mathrm{T}$ & 22 & 21 & 37 & N.A. \\
\hline TM & 38 & 37 & 63 & 46 \\
\hline M & 44 & 42 & N.A. & 54 \\
\hline$N$ & 35 & N.A. & N.A. & N.A. \\
\hline
\end{tabular}

C. Distribution of units by response type and location

\begin{tabular}{lcrrrrrr}
\hline $\begin{array}{l}\text { Response } \\
\text { type }\end{array}$ & $\begin{array}{c}\text { Total no. } \\
\text { of units }\end{array}$ & DLP & LP & VLP & MP & NRTP & VLL \\
\hline $\mathrm{T}$ & 22 & 9 & 1 & 0 & 0 & 0 & 12 \\
$\mathrm{TM}$ & 38 & 20 & 12 & 0 & 0 & 0 & 6 \\
$\mathrm{M}$ & 44 & 3 & 13 & 1 & 0 & 27 & 0 \\
$\mathrm{~N}$ & 35 & 0 & 4 & 7 & 19 & 5 & 0 \\
\hline
\end{tabular}

Shown is a breakdown of the total number of units that were recorded and analyzed. A lists the total number of recordings, the recording that altered their firing pattern to some aspect of the conditioning process (i.e., response to tone, or learning related activity), those recordings that showed an auditory response (either an auditory response alone or an auditory response followed by a model), and those recordings that showed a model response (either a model response alone or a auditory response followed by a model). Because some individual units showed both an auditory and model response, the total auditory and model response units is greater than the total responding units. $B$ lists the number of units recorded for each response type [(T) tone response; $(T M)$ tone plus model response; $(M)$ model response; $(N)$ no detectable response]. It also lists the percentage of responding, auditory, and model units that each response type represents (these percentages were derived from the total number of responding units). (N.A.) Data not available. $C$ lists the number of recordings, by response type, that were found in the dorsolateral pontine nucleus (DLP), lateral pontine nucleus (LP), ventrolateral nucleus (VL), medial pontine nucleus (MP), nucleus reticularis tegmenti pontis (NRTP), and ventral nucleus of the lateral lemniscus (VLL).

evoked responses. However, it abolished completely any learning-related activity that may have been present in the pontine nuclei. A two-factor analysis of variance (ANOVA) (normal versus cooling) with six repeated measures (three CS and three US epochs) revealed a main effect of cooling $\left(F_{1,324}=73.11, P<0.0001\right)$. Figure 2 illustrates the average $\mathrm{z}$ scores of those units that showed a tone response followed by a model response during normal training versus training during cooling. In this figure there are significant increases in activity immediately after the tone onset followed by a more gradual increase in activity that peaks just after the onset of the air puff before decreasing toward baseline later in the US period. During cooling the increased activity just after the tone onset remains, whereas activity in the remainder of the CS period is considerably diminished. CS epoch 2 is still significantly elevated, but this is likely attributable to some auditory units that extended into this epoch. At CS epoch 3 there is no significant unit activity above baseline during interpositus cooling. Interestingly, the average $z$ score for the 84-msec epoch immediately after the air puff onset was still significant. This appears be a result of an unmasking of a second auditory-evoked response caused by the

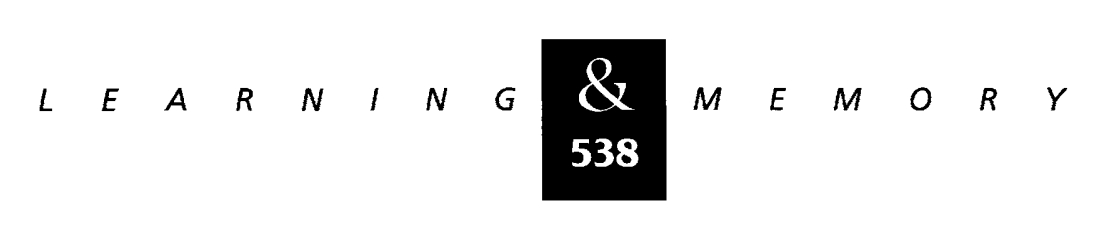




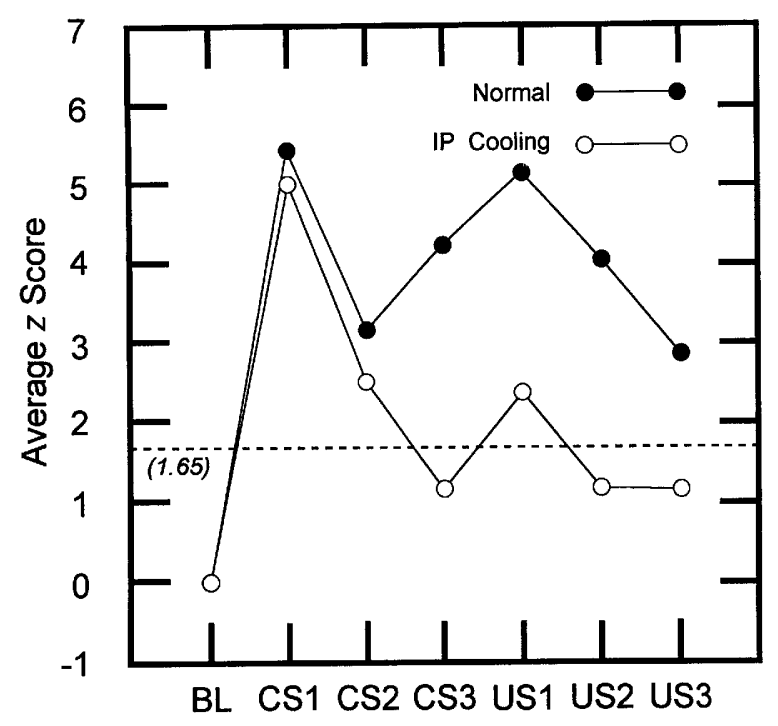

Figure 2: This graph illustrates the average $z$ scores for units that were classified as tone plus model responses. The $x$-axis represents the six epochs. Tone onset occurs at the onset of epoch CS1, air-puff onset occurs at the onset of epoch US1. The dotted line represents a onetailed 0.05 significance level $(z=1.65)$. Black dots represent average $z$ scores during normal training and white dots represent average $z$ scores during interpositus cooling. Cooling abolishes activity in epoch CS3-the time just before the air-puff onset-where learning-related activity would be expected.

rush of air in the nozzle. We were able to determine that this second response was auditory in nature, rather than a somatosensory response evoked by the air puff, by moving the air puff away from the eye and directed over the rabbit's head. This manipulation removed the somatosensory confound and left only the sound of the air puff. Moving the air puff did not abolish this second response, thus our conclusion that it was auditory in nature.

Figure $3 \mathrm{~A}$ is an example from one animal with recordings from the dorsolateral pontine nucleus during normal training. The unit response is only evoked by the sound of the tone and the sound of the air puff ( $\mathrm{T}$ response). Figure 3B shows the behavior and unit response in the same animal and recording location during interpositus cooling. The CR has been abolished and the UR remains as does the auditory response to the tone and air puff. Figure $3 \mathrm{C}$ is an example of one animal during normal training with a recording electrode located in the lateral pontine nucleus. This recording shows a tone-evoked response that is followed by a learn- ing-related increase in activity. Figure 3D shows the behavior and unit response in the same animal and recording location during interpositus cooling. As in Figure 3B, the CR is abolished and the UR remains intact. The tone evoked response is still present, whereas the learning-related increase in activity is abolished. Interestingly, a second auditory response to the air puff is unmasked and is seen as an increase in activity that immediately follows the onset of the air puff. This response remained even when the air puff was directed over the rabbit's head. This manipulation kept the sound of the air puff constant but removed the somatosensory stimulation. Frequently we encountered this type of response pattern when recording from the dorsolateral and lateral pontine nuclei and cooling the interpositus.

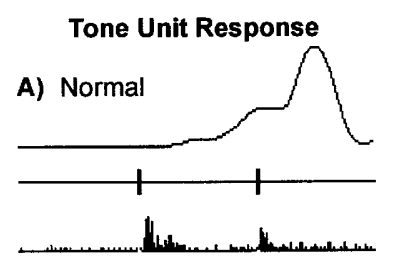

Tone + Model Unit Response

C) Normal

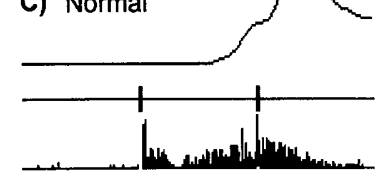

B) IP Cooling
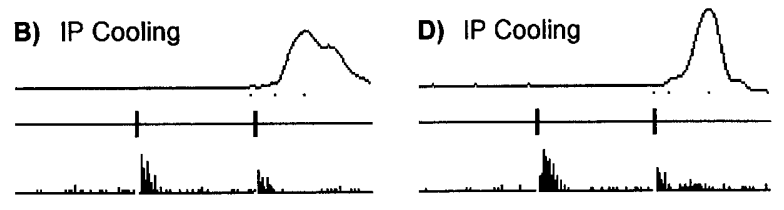

Figure 3: Examples of typical behavioral and electrophysiological responses seen with normal training and training with interpositus cooling while recording from the pontine nuclei. For each panel the top line represents the position of the NM, the next line is the interstimulus interval (ISI) with the left hatch mark representing the tone onset and the right hatch mark representing the air-puff onset. Below the ISI gauge is the associated peristimulus histogram of unit activity summed over nine trials. (A) T responses during normal training, with an auditory-evoked response to the tone and airpuff. $(B)$ From the same recording location during interpositus (IP) cooling. Note that the auditory-evoked response is still present. $(C)$ From the same animal at a different recording location in the pontine nuclei during normal training. These were classified a TM units because there was an auditory-evoked response followed by a learning-related increase in activity. (D) Units obtained from the same location as in $C$ during IP cooling. Note that the learning-related activity is abolished completely, whereas the tone-evoked response is still present. In this example, after the US onset, a second auditory-evoked response (to the sound of the air puff) is unmasked.

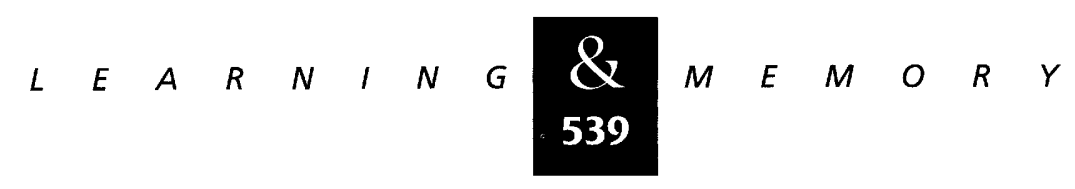


Clark et al.

Figure 4 illustrates the average unit $\mathrm{z}$ scores for $M$ responses. This graph illustrates the abolition of the unit responses associated with cooling the interpositus. A two-factor ANOVA (normal versus cooling) with six repeated measures (three CS and three US epochs) revealed a main effect of cooling $\left(F_{1,408}=823, P<0.0001\right)$. During normal training the activity began to increase in CS epoch 1 and continued to increase to CS epoch 3, at which point it began to decline slowly toward baseline. During cooling the unit activity never reached a significant level of activity in any of the CS or US epochs. Contrast this with Figure 2, which shows continued elevated activity in the CS1, CS2, and US1 epochs during interpositus cooling attributable to the continued influence of an auditoryevoked response to the tone and air puff. After cooling, all the units we continued to sample returned to their precooling firing patterns, which had no discernible change in any of the response characteristics.

\section{RECORDINGS DURING COOLING FACIAL NUCLEUS}

Recordings obtained from the pontine nuclei in rabbits with a cooling probe placed near the

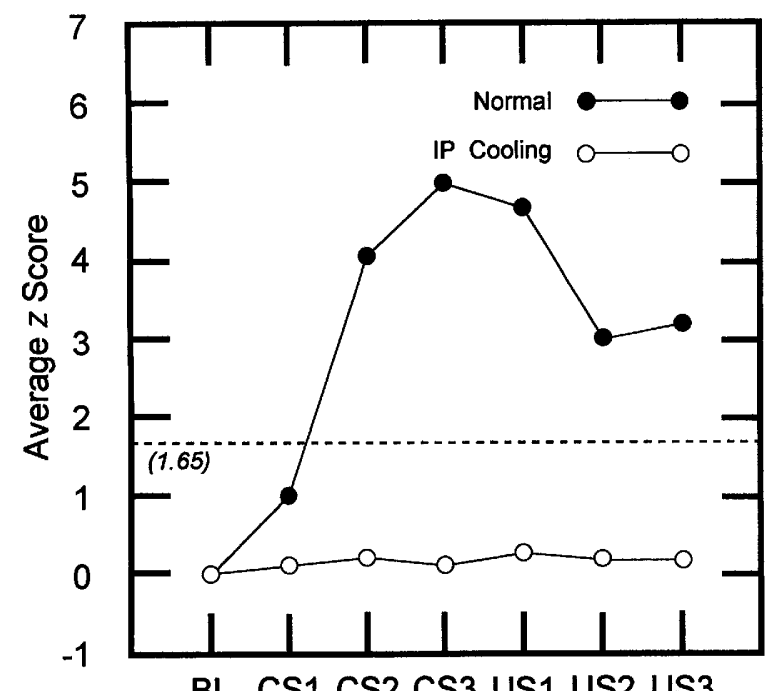

Figure 4: This graph illustrates the average $z$ scores for units that were classified as model $(M)$ responses. The $x$-axis represents the six epochs. Tone onset occurs at the onset of epoch CS1, air puff onset occurs at the onset of epoch US1. The dotted line represents a one-tailed 0.05 significance level $(z=1.65)$. Black dots represent average $z$ scores during normal training and white dots represent average $z$ scores during interpositus cooling. Cooling abolishes $\mathrm{M}$ unit responses. facial nucleus showed the same general patterns of response. However, unlike interpositus cooling, when the facial nucleus was cooled, the response patterns of the pontine nuclei continued to show increased activity in the CS and US epochs. Recording sites with TM responses continued to show robust tone-evoked responses and elevated activity associated with the learned, but no longer expressible response (i.e., the unit activity remained but motor movements were abolished). $\mathrm{z}$ Score analysis showed that on the average the responses tended to be smaller during cooling than during normal training, although this difference did not reach significance $\left(F_{1,108}=2.05, p>0.1\right.$, not significant). However, these units were significantly elevated over baseline. This was also true for $M$ responses during facial cooling. Although there appeared to be a slight decrease in $\mathrm{z}$ scores during cooling, the basic form of the unit response did not change. That is, the units continued to model the learned response and the density of units were not reduced significantly $\left(F_{1,96}=2.48, P>0.1\right.$, not significant).

Figure 5 is a graph of average TM responses recorded from the lateral pontine nuclei during normal training and training while cooling the facial nucleus. Notice that during cooling the significant increase in activity is still present in the pontine nuclei. Figure 6 is an example of one animal's NM behavior, facial EMG, and recordings from the lateral pontine gray during normal training and training while cooling. Notice that both the learned and unconditioned NM and EMG response have been abolished, whereas the learning-related model is still discernible.

\section{Discussion}

The behavioral results of the present study are clear. In well-trained animals, cooling the interpositus nucleus abolished completely the CR without decreasing the UR significantly. The selective effect of reversible lesions of interpositus on the CR and not the UR is consistent with previous reversible interpositus lesion studies (Clark et al. 1992; Krupa et al. 1993; Nordholm et al. 1993) and numerous permanent lesion studies (see Steinmetz et al. 1992). Cooling the facial nucleus abolished completely the animal's ability to execute the conditioned and unconditioned response. This finding extends the results of Zhang and Lavond (1991) who found that cooling the facial nucleus abol-

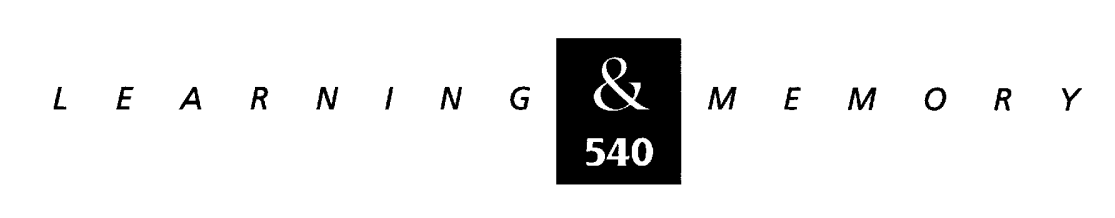




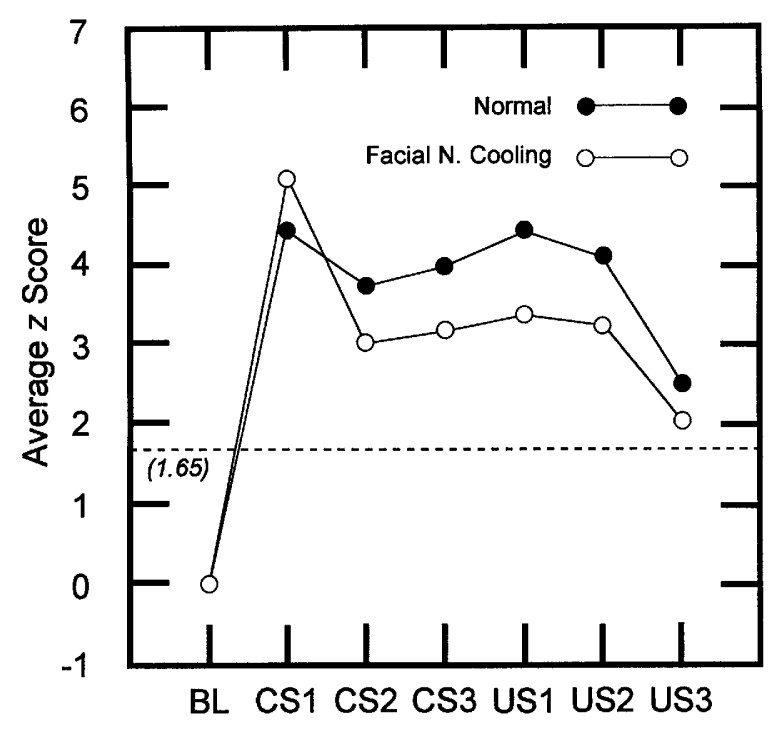

Figure 5: This graph illustrates the average $z$ scores for units that were classified as tone plus model (TM) responses. The $x$ axis represents the six epochs. Tone onset occurs at the onset of epoch CS1, air-puff onset occurs at the onset of epoch US1. The dotted line represents a one-tailed 0.05 significance level $(z=1.65)$. Black dots represent average $z$ scores during normal training and white dots represent average $z$ scores during facial nucleus cooling. Cooling the facial nucleus did not abolish pontine unit activity to tone or the learning activity.

ished completely facial EMG CRs and URs. The present study demonstrated that this effect is also true of NM CRs and URs and is consistent with studies using reversible muscimol lesions of the facial nucleus, which also abolish completely NM responses (Krupa et al. 1996).

Several conclusions can be made from the electrophysiological results of the present study. Multiple unit extracellular recordings from various regions of the pontine gray show an increase in unit activity that models the learned behavior. Many of these models were preceded by a phasic tone-evoked response. This evoked response had a rapid onset and generally returned toward baseline within $100 \mathrm{msec}$. This observation is consistent with the idea that the pontine nuclei, and specifically the lateral and dorsolateral regions, are involved in relaying auditory $\mathrm{CS}$ information to the cerebellum by their massive mossy fiber projection through the middle cerebellar peduncle. The fact that auditory-evoked responses were present in the lateral and dorsolateral regions of the pontine nuclei is consistent with previous electrophysiological and anatomical studies indicating that this re- gion of the pontine nuclei receives primary auditory information (Aitkin and Boyd 1978; Kandler and Herbert 1991). Injections of fast blue into the lateral region of the pontine nuclei have been shown to label the contralateral ventral cochlear nucleus and to a lesser extent, the contralateral dorsal cochlear nucleus, the ipsilateral superior olive, and the ipsilateral inferior colliculus (Steinmetz et al. 1987).

The observation that unit models are present in the pontine gray has been reported previously (McCormick et al. 1983). There are three possible explanations for this neuronal model. (1) The model is feedback from the behavioral execution of the CR. (2) The neuronal activity associated with the learned behavior is generated by the cells in the pontine nuclei. (3) The model is feedback from some afferent structure. The first explanation is the weakest because if the model was a result of behavioral feedback, then the units should model both the CR and UR-they do not. Instead, like recording from the interpositus, they modeled only the learned response. Because learning-related unit activity was still observable in specific regions of the pontine gray in the absence of a behavioral response when there was facial nucleus cooling, we conclude that this activity is not dependent on the behavioral response and thus it is not feedback from the eye blink. The second explanation, that the cells in the pontine gray are responsible for the generation of the learning-related activity, can also be ruled out. The unit activity related to the learned response, but not the tone-evoked re-

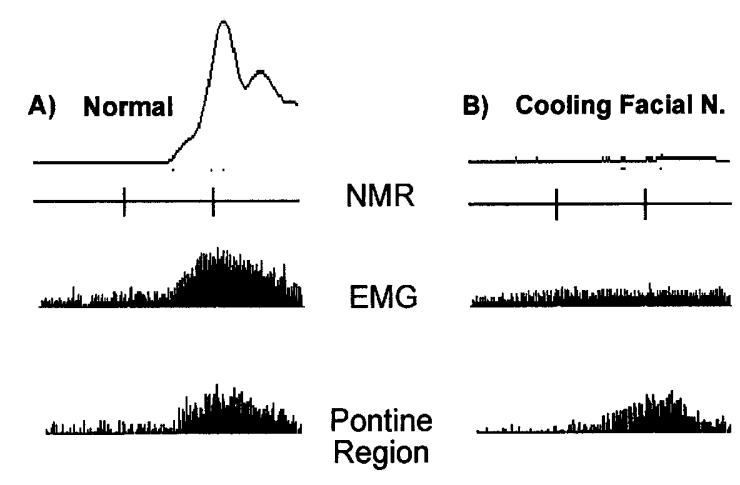

Figure 6: NM behavior, EMG behavior, and pontine recordings from animal 94-089 during normal training and training with facial cooling. This figure is a similar illustration to Fig. 3, except EMG recording from the eye muscles are also included. Note that cooling the facial nucleus abolishes the NM response and the facial EMG response, but not the activity in the pontine nuclei.

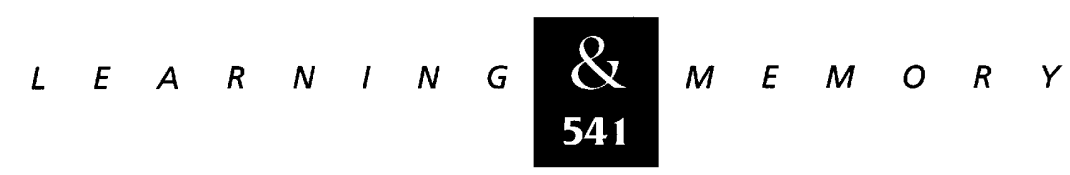


sponse, was abolished with interpositus cooling. If cooling the interpositus had a general effect of suppressing all activity in these cells, then our results would be confounded. However, because many units continued to respond to auditory stimuli, it is unlikely that they were prevented physically from showing any learning-related activity. Our data clearly implicate the third explanation, that learning-related unit activity is projected to the pontine gray. The learning-related activity seen in the pontine gray is dependent on a normally functioning interpositus nucleus. This study cannot address directly the question of how this information is relayed to the pontine nuclei. However, the simplest explanation would be from the direct projections from the contralateral interpositus nucleus (Tsukahara and Bando 1970; Brodal et al. 1972; Yeun et al. 1974; Kitai et al. 1976).

Importantly, the results from cooling the interpositus and recording from the pontine nuclei are different from recording from the pontine nuclei while cooling the red nucleus (Cartford et al., this issue; M.C. Cartford, E. Gohl, M. Singson, E. Wang, L. Tasa, and D.G. Lavond, unpubl.). This study found that cooling the red nucleus did not abolish the learning-related activity in the central region of the lateral pontine nuclei. Interestingly, this region receives direct projections from the interpositus $(\mathrm{J}$. Lockard and D.G. Lavond, unpubl.). This pattern of projections fits with the regions in the present study and in Cartford et al. (this issue) that typically exhibited learning-related increases in activity. This projection can also explain why cooling the interpositus could abolish this activity, whereas cooling the red nucleus would leave this response increase intact.

We have suggested that the learning-related activity in the pontine nuclei is received from the interpositus directly (M.C. Cartford, E. Gohl, M. Singson, E. Wang, L. Tasa, and D.G. Lavond, unpubl.) or indirectly. Now we can speculate as to the functional significance of this property. Because numerous studies have implicated the pontine nuclei as relaying auditory CS information to the cerebellum and receiving information concerning the development of the learned response (the model) it might be surmised that this feedback may serve to modify pontine activity so that the particular CS becomes more salient (i.e., a sharpening of tuning curves to effect selective attention, for example) and thus increasing sensitivity to the CS (Woody et al. 1992), and consequently, more consistent CR performance. In this regard we note that using a two-tone discrimination procedure (400 and $1600 \mathrm{~Hz}$ tones), Richards et al. (1991) reported that in well-trained animals, some single cells in the dorsolateral pons showed a larger evoked response to the CS+ than the CS-, regardless of which tone served as the CS+. Finally, a recent study, which measured the stimulation thresholds required to elicit eye blinks with either pontine or interpositus stimulation before and after classical conditioning using pontine stimulation as the CS and air puff as the US, found that after classical conditioning, pontine stimulation thresholds were reduced, whereas interpositus thresholds were not (J. Tracy, J.K. Thompson, D.J. Krupa, and R.F. Thompson, in prep.). They also found that stimulating electrodes located in the lateral and dorsolateral pontine nuclei resulted in faster acquisition than electrodes located in other regions of the pontine gray. The regions that resulted in faster acquisition are the same ones that in the present study showed unit models and CS evoked responses. Therefore, this suggests that the projection from interpositus to the pontine nuclei may serve to facilitate the acquisition of the learned behavior.

A final consideration involves the recordings obtained from NRTP. In the present study we found 27 units that showed $M$ type response patterns. Although these results clearly indicate that this structure is involved in the classically conditioned eye-blink response, the nature of this involvement is unclear. Recent electrophysiological and lesion experiments suggest that NRTP is part of the pathway, which includes the cerebellum, subserving the horizontal optokinetic nystagmus response (for example, see Cazin et al. 1980). Recording studies also suggest its involvement in saccade, head-velocity, and smooth-pursuit related responses of the eyes (for example, see Curthoys et al. 1981). This evidence indicates that neurons of the NRTP are involved in many aspects of oculomotor function. The firing patterns and connections of the NRTP suggest that it may function in concert with the deep cerebellar nuclei as part of a positive feedback loop with the cerebellum for control or modulation of certain types of eye movements. It is conceivable that this structure might also function in a similar way in the classically conditioned eye-blink response.

Anatomical (Gerrits and Voogd 1987; GonzaloRuiz and Leichnetz 1990; Steinmetz and Sengelaub 1992; Mihailoff 1993) and physiological (Tsukahara et al. 1983) studies indicate that NRTP sends a projection to the interpositus and that this projection

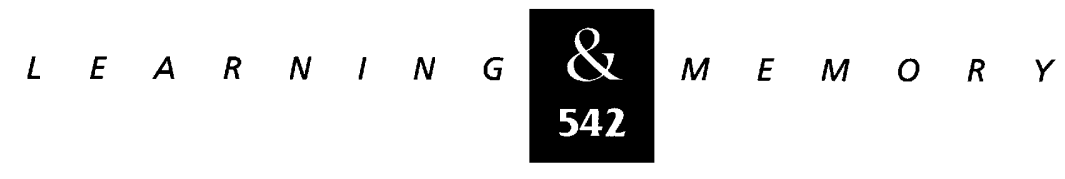


may be extensive (Mihailoff 1993, p.135). Other anatomical studies also indicate that the interpositus projects back to the NRTP (Torigoe et al. 1986; Gonzalo-Ruiz and Leichnetz 1990). This reciprocal connection could serve as feedback to the cerebellum concerning the eye blink or in the coordination of an eyelid/NM blink and eyeball movement. In any case, the present results indicate that NRTP warrants further study to characterize more fully its involvement in this paradigm.

In summary, these data support previous research that implicate the pontine nuclei in conveying auditory CS information to the cerebellum. In addition, the present study indicates that the learning-induced changes exhibited by this region is a consequence of the modified (learning-induced) output from the cerebellum and is consistent with the notion that the essential plasticity associated with the conditioned eye-blink response is a function of cerebellar neural elements.

\section{Acknowledgments}

This work was supported by grants MH 51197 (DGL), NRSA 1F32MH11154-01 (REC), NSF BNS8718300, ONR N00014-88K-0112 (RFT) from the National Institute of Mental Health. We thank R.F. Thompson for his advise and support and Claire Cartford for her helpful comments.

\section{References}

Aitkin, L.M. and J. Boyd. 1978. Acoustic input to the lateral pontine nuclei. Hearing Res. 1:67-77.

Brooks, V.B. 1983. Study of brain function by local, reversible cooling. Review of Physiol. Biochem. Pharmacol. 95: 1-109.

Brodal, A. and J. Jansen. 1946. The pontocerebellar projection in the rabbit and cat. Experimental investigations. J. Comp. Neurol. 84: 31-118.

Brodal, A., A. Destombes, A. Lacerda, and P. Angaut. 1972. A cerebellar projection onto the pontine nuclei. An experimental anatomical study in the cat. Exper. Brain Res. 19: 115-139.

Cartford, M.C., E.B. Gohl, M. Singson, and D.G. Lavond. 1997. The effects of reversible inactivation of the red nucleus on learning-related and auditory-evoked unit activity in the pontive nuclei of classically conditioned rabbits. Learn. \& Mem. (this issue).

Cazin, L., W. Precht, and J. Lannou. 1980. Pathways mediating optokinetic responses of vestibular nucleus neurons in the rat. Pflügers. Arch. 384: 19-29.

Cegavske, C.F., R.F. Thompson, M.M. Patterson, and I. Gormezano. 1976. Mechanism of efferent control of the reflex nicitating membrane response in the rabbit. J. Comp. Physiol. Psychol. 90: 411-423.

Clark, R.E. and D.G. Lavond. 1993. Reversible lesions of the red nucleus during acquisition and retention of a classically conditioned behavior in rabbits. Beh. Neurosci. 107: $264-270$.

1996. Neural unit activity in the trigeminal complex with interpositus or red nucleus inactivation during classical eyeblink conditioning. Behav. Neurosci. 110: 13-21.

Clark, R.E., A.A. Zhang, and D.G. Lavond. 1992. Reversible lesions of the cerebellar interpositus nucleus during acquisition and retention of a classically conditioned behavior. Behav. Neurosc. 106: 879-888.

1997. The importance of cerebellar cortex and facial nucleus in acquisition and retention of eyeblink/NM conditioning: Evidendence for critical unilateral regulation of the conditioned response. Neurobiol. Learn. Mem. 67: 96-111.

Curthoys, I.S., S. Nakao, and C.H. Markham. 1981. Cat medial pontine reticular neurons related to vestibular nystagmus: Firing pattern, location and projections. Brain Res. 222: 75-94.

Gerrits, N.M. and J. Voogd. 1987. The projection of the nucleus reticularis tegmenti pontis and adjacent regions of the pontine nuclei to the central cerebellar nuclei in the cat. J. Comp. Neurol. 258: 52-69.

Gonzalo-Ruiz, A. and G.R. Leichnetz. 1990. Connections of the caudal cerebellar interpositus complex in a new world monkey (Cebus apella). Brain Res. Bull. 25: 919-927.

Kandler, K. and H. Herbert. 1991. Auditory projections from the cochlear nucleus to pontine ad mesencephalic reticular nuclei in the rat. Brain Res. 562: 230-242.

Kim, J.J., R.E. Clark, and R.F. Thompson. 1995. Hippocampectomy impairs the memory of recently, but not remotely, acquired trace eyeblink responses. Behav. Neurosci. 109: 195-203.

Kitai, S.T., J.D. Kocsis, and T. Kiyohara. 1976. Electrophysiological properties of nucleus reticularis tegmenti pontis cells. Antidromic and synaptic activation. Exper. Brain Res. 24: 295-309.

Krupa, D.J., J.K. Thompson, and R.F. Thompson. 1993. Localization of a memory trace in the mammalian brain. Science 260: 989-991.

Krupa D.J., J. Weng, and R.F. Thompson. 1996. Inactivation of brainstem motor nuclei blocks expression but not acquisition of the rabbit's classically conditioned eyeblink response. Behav. Neurosci. 110: 219-227.

Lavond, D.G. and J.E. Steinmetz. 1989. An inexpensive interface for IBM PC/XT and compatibles. Behav. Res. Methods Instru. Computers 21: 435-440. 
Clark et al.

Lavond, D.G., D.A. McCormick, G.A. Clark, D.T. Holmes, and R.F. Thompson. 1981. Effects of ipsilateral rostral pontine reticular lesions on retention of classically conditioned nictitating membrane and eyelid responses. Physiol. Psychol. 9: $335-339$.

Lavond, D.G., J.J. Kim, and R.F. Thompson. 1993. Mammalian brain substrates of aversive classical conditioning. Annu. Rev. Psychol. 44: 317-342.

McCormick, D.A., D.G. Lavond, and R.F. Thompson. 1983. Neuronal responses of the rabbit brainstem during performance of the classically conditioned nictitating membrane (NM)/eyelid response. Brain Res. 271: 73-88.

Mihailoff, G.A. 1993. Cerebellar nuclear projections from the basilar pontine nuclei and nucleus reticularis tegmenti pontis as demonstrated with PHA-L tracing in the rat. J. Comp. Neurol. 330: 130-146.

Nordholm, A.F., J.K. Thompson, C. Dersarkissian, and R.F.Thompson. 1993. Lidocaine infusion in a critical region of cerebellum completely prevents learning of the conditioned eyeblink response. Behav. Neurosci. 107: 882-886.

Olds, J., J.F. Disterhoft, M. Segal, C.L. Kornblith, and R. Hirsh. 1972. Learning centers of rat brain mapped by measuring latencies of conditioned unit responses. $J$. Neurophysiol. 35: 202-219.

Richards, W.G., T.N. Ricciardi, and J.W. Moore. 1991. Activity of spinal trigeminal pars oralis and adjacent reticular formation units during differential conditioning of the rabbit nictitating membrane response. Behav. Brain Res. 44: 195-204.

Solomon, P.R., J.L. Lewis, J. LoTurco, J.E. Steinmetz, and R.F. Thompson. 1986. The role of the middle cerebellar peduncle in acquisition and retention of the rabbits classically conditioned nictitating membrane response. Bull. Psychon. Soc. 24: 75-78.

Steinmetz, J.E. 1990. Neuronal activity in the rabbit interpositus nucleus during classical NM- conditioning with a pontine-nucleus-stimulation CS. Psycholog. Sci. 1: 378-382.

Steinmetz, J.E. and D.R. Sengelaub. 1992. Possible conditioned stimulus pathway for classical eyelid conditioning in rabbits. 1. Anatomical evidence for direct projections from the pontine nuclei to the cerebellar interpositus nucleus. Behav. Neural Biol. 57: 103-115.

Steinmetz, J.E., D.G. Lavond, and R.F. Thompson. 1985. Classical conditioning of the rabbit eyelid response with mossy fiber stimulation as the conditioned stimulus. Bull. Psychon. Soc. 23: 245-248.

Steinmetz, J.E., D.J. Rosen, P.F. Chapman, D.G. Lavond, and R.F. Thompson. 1986. Classical conditioning of the rabbit eyelid response with a mossy fiber stimulation CS. I. Pontine nuclei and middle cerebellar peduncle stimulation. Behav.

Neurosci. 100: 871-880.
Steinmetz, J.E., C.G. Logan, D.J. Rosen, J.K. Thompson, D.G. Lavond, and R.F. Thompson. 1987. Initial localization of the acoustic conditioned stimulus projection system to the cerebellum essential for classical eyelid conditioning. Proc. Natl. Acad. Sci. 84: 3531-3535.

Steinmetz, J.E., D.G. Lavond, and R.F. Thompson. 1989. Classical conditioning in rabbits using pontine nucleus stimualtion as a conditioned stimulus and inferior olive stimulation as an unconditioned stimulus. Synapse 3: $225-233$.

Steinmetz, J.E., D.G. Lavond, D. Ivkovich, C.G. Logan, and R.F. Thompson. 1992. Disruption of classical eyelid conditioning after cerebellar lesions: damage to a memory trace system or a simple performance deficit? J. Neurosci. 12: $4403-4426$.

Thompson, R.F. 1976. The search for the engram. Am. Psychol. 31: 209-227.

Torigoe, Y., R.H.I. Blanks, and W. Precht. 1986. Anatomical studies on the nucleus reticularis tegmenti pontis in the pigmented rat. II. Subcortical afferents demonstrated by the retrograde transport of horseradish peroxidase. J. Comp. Neurol. 243: 88-105.

Tsukahara, N. and T. Bando. 1970. Red nuclear and interposate nuclear excitation of pontine nuclear cells. Brain Res. 19: 295-298.

Tsukahara, N., T. Bando, F. Murakam, and Y. Oda. 1983. Properties of cerebello-precerebellar reverberating circuits. Brain Res. 274: 249-259.

Woody, C.D., X.F. Wang, and E. Gruen. 1992. Unit activity to click CS changes in dorsal cochlear nucleus after conditioning. Neuroreport 3: 385-388.

Yuen, H.R., M. Dom, and G.F. Martin. 1974.

Cerebellopontine projections in the American opossum. A study of their orgin, distribution and overlap with fibers from the cerebral cortex. J. Comp. Neurol. 154: 257-286.

Zhang, J., H. Ni, and R.M. Harper. 1986. A miniaturized cryoprobe for functional neuronal blockade in freely moving animals. J. Neurosci. 16: 79-87.

Received January 28, 1997; accepted in revised form March 26, 1997.

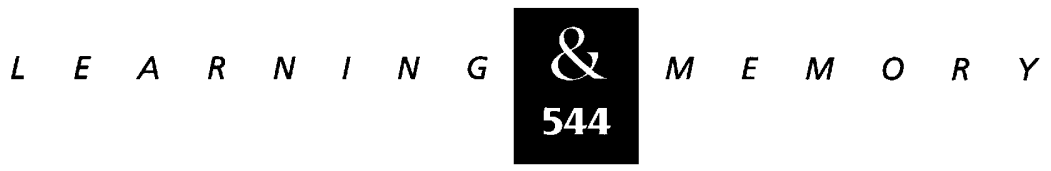




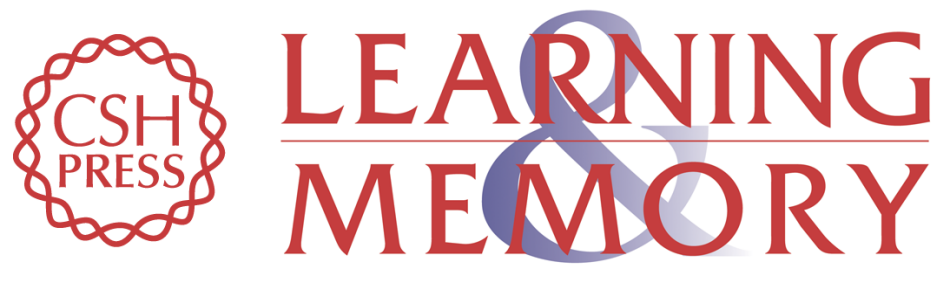

\section{The learning-related activity that develops in the pontine nuclei during classical eye-blink conditioning is dependent on the interpositus nucleus.}

R E Clark, E B Gohl and D G Lavond

Learn. Mem. 1997, 3:

Access the most recent version at doi:10.1101//m.3.6.532

References This article cites 41 articles, 3 of which can be accessed free at: http://learnmem.cshlp.org/content/3/6/532.full.html\#ref-list-1

License

Email Alerting Receive free email alerts when new articles cite this article - sign up in the box at the Service top right corner of the article or click here. 